\title{
Study on Ion Exchange behavior of Nuclear Grade Resin AuchliteARA9366 Chemically Degraded in HydrogenPeroxide Medium
}

\author{
ASHOK NARHARI PATANGE* \\ Department of Chemistry, Bhavan's College, Munshi Nagar, \\ Andheri (West),Mumbai, Maharashtra 400058, India. \\ *Corresponding Author e-mail: ashokpatange78@gmail.com \\ http://dx.doi.org/10.13005/ojc/330255
}

(Received: January 03, 2017; Accepted: March 22, 2017)

\begin{abstract}
The ion exchange resins are important material for study of various uni-univalent and unibivalent ion exchange reactions for the separation, purification and the treatment of industrial effluent's and nuclear waste. In the current investigation attempts were done to evaluate the performance and the selectivity behavior of peroxide degraded resins viz AuchliteARA-9366 towards the $\mathrm{Br}$ and $\mathrm{I}$ ions from the external solution. AuchliteARA-9366 resins in chloride form were subjected to Hydrogen peroxide degradation separately on the magnetic stirrer for $24 \mathrm{~h}$ at room temperature using 20\% (6 volume) and 30\% (9 volume) $\mathrm{H}_{2} \mathrm{O}_{2}$. The ion exchange equilibrium study of the peroxide degraded AuchliteARA-9366 resin in chloride form were done separately with $\mathrm{KBr}$ and $\mathrm{KI}$ solution of concentrations range from $0.01 \mathrm{M}$ to $0.1 \mathrm{M}$ at the temperature $30.0^{\circ}, 35.0^{\circ}, 40.0^{\circ}$ and $45.0^{\circ} \mathrm{C}$ for $3 \mathrm{~h}$ and the equilibrium constants $(K)$ values for $\mathrm{Cl} / \mathrm{l}$ and $\mathrm{Cl} / \mathrm{Br}$ ion exchange reactions were determined. It was found that during $\mathrm{Cl} / \mathrm{l}-$ ion exchange reactions, the $K$ values of AuchliteARA-9366 resin degraded using $20 \% \mathrm{H}_{2} \mathrm{O}_{2}$ were found to be decreases from $37.28 \times 10^{-2}$ to $15.61 \times 10^{-2}$ which was higher than the $K$ values observed for the resin degraded using $30 \% \mathrm{H}_{2} \mathrm{O}_{2}$ which decreases from $20.53 \times 10^{-2}$ to $15.54 \times 10^{-2}$ with rise in temperature from $30.0-45.0^{\circ} \mathrm{C}$. Similar results were observed during $\mathrm{Cl} /$ $\mathrm{Br}$ ion exchange reactions for the resins AuchliteARA-9366. The equilibrium constant $(K)$ values were found to be decreases with rise in temperature shows that both $\mathrm{Cl} / \mathrm{l}-$ and $\mathrm{Cl} / \mathrm{Br}$ ion exchange reactions were exothermic in nature and which was further supported by negative enthalpy $\left(\Delta \mathrm{H}^{0}\right)$ and entropy $\left(\Delta \mathrm{S}^{0}\right)$ values. The equilibrium constant $(\mathrm{K})$ values of peroxide degraded resins indicates that resins effectively oxidized with increase in the concentration of $\mathrm{H}_{2} \mathrm{O}_{2}$ from $20 \%$ to $30 \%$ which were also seen in SEM micrographs and FTIR spectrum of the resin. The results obtained from the present study will be helpful in understanding the effects of hydrogen peroxide degradation on the performance and halide ion selectivity behavior of ion exchange resins AuchlitARA-9366.
\end{abstract}

Keywords: hydrogen peroxide degradation; AuchliteARA-9366; anion exchanger; nuclear and industrial grade resin; enthalpy. 


\section{INTRODUCTION}

The AuchliteARA-9366 was a strong base nuclear grade anion exchange resin having cross linked polystyrene matrix. Strongly basic anion exchange resins can be useful for ${ }^{1}$ waste water treatment in large number of food, chemical and bio industry whereas the anion exchange resin with benzyllic ternary ethyl or methyl ammonium groups were chemically unstable and not suitable above $60^{\circ}-70^{\circ} \mathrm{C}$ temperatures in the hydroxide form ${ }^{2}$. Organic ion exchange resins were more versatile and selective than inorganic ion exchange resins and readily available to fulfil the demands of the various industries ${ }^{3}$.The inorganic ion exchangers were more selective towards the separations of specific radioactive ions like $\mathrm{Cs}^{+}$and $\mathrm{Sr}^{+}$from nuclear waste than the organic exchangers ${ }^{5}$.The inorganic exchangers 6 becomes more useful in nuclear industry than conventional organic resins especially in high purity water applications ${ }^{7}$. Considering the extensive industrial applications of ion exchange resin, in the present investigation attempts were made to study the performance and selectivity behavior of hydrogen peroxide (20\%\&30\%) degraded resins AuchliteARA$9366^{8}$.The scanning electron microscopy (SEM) and Fourier Transform Infrared Spectroscopy (FTIR) ${ }^{9}$ were used to study the surface morphology and to recognizing the degradation pattern of the resin AuchliteARA-9366 in hydrogen peroxide medium. The above resins in chloride form were subjected to peroxide degradation using 20\% (6 volume) and $30 \%$ (9 volume) $\mathrm{H}_{2} \mathrm{O}_{2}$ and ion exchange equilibrium studies of the resins were carried out to determine standard free energy $\left(\Delta \mathrm{G}^{0}\right)$, entropy $\left(\Delta \mathrm{S}^{0}\right)$, enthalpy change $\left(\Delta \mathrm{H}^{0}\right)$ and mode of their chemical degradation.

\section{MATERIALS AND METHODS}

The anion exchange resin AuchliteARA9366 in hydroxide form was purchased from Auchtel chemical Products Ltd.,Lower Parel,Mumbai,India. The various physical and chemical properties of the resins AuchliteARA-9366 was given in Table 1

\section{Chemical degradation of resins}

The performance of chemically degraded AuchliteARA-9366 resins was studied by exposing it to hydrogen peroxide $\left(20 \% \mathrm{H}_{2} \mathrm{O}_{2} \& 30 \% \mathrm{H}_{2} \mathrm{O}_{2}\right)$ medium. In order to bring about hydrogen peroxide (20\% $\mathrm{H}_{2} \mathrm{O}_{2} \& 30 \% \mathrm{H}_{2} \mathrm{O}_{2}$ ) degradation, $25 \mathrm{~g}$ of the resins in chloride form are transferred separately in $100 \mathrm{~mL}$ round bottom flask containing $50 \mathrm{~mL}$ of $20 \%$ $\mathrm{H}_{2} \mathrm{O}_{2}$ and $30 \% \mathrm{H}_{2} \mathrm{O}_{2}$ and the mixture was stirred on the magnetic stirrer for $24 \mathrm{~h}$. The ished chemically degraded resins in chloride form are air dried over $\mathrm{P}_{2} \mathrm{O}_{5}$ in desiccators and used for further studies.

Conditioning and equilibration of chemically degraded resins in hydrogen peroxide $(20 \%$ $\mathrm{H}_{2} \mathrm{O}_{2} \& 30 \% \mathrm{H}_{2} \mathrm{O}_{2}$ ) medium

In order to completely convert the resins AuchliteARA9366 in chloride form, about $80 \mathrm{~g}$ of resin are placed in glass column $60 \mathrm{~cm}$ long and $2.5 \mathrm{~cm}$ in diameter ${ }^{10}$ and eluted with $1 \mathrm{~L}$ of $1 \mathrm{M}$ potassium chloride solution at the rate of $2 \mathrm{~mL} / \mathrm{min}$. the resin is then washed with distilled water and methanol to remove excess of chloride ions and are air dried over $\mathrm{P}_{2} \mathrm{O}_{5}$ in desiccators, stored in stoppard bottle and used for further study ${ }^{11}$. The ion exchange equilibration study of the above $20 \%$ $\mathrm{H}_{2} \mathrm{O}_{2} \& 30 \% \mathrm{H}_{2} \mathrm{O}_{2}$ degraded AuchliteARA9366 in chloride form were carried out separately for $3 \mathrm{~h}$ with $\mathrm{KBr}$ and $\mathrm{KI}$ solutions ${ }^{12}$ of different concentration from $0.01 \mathrm{M}, 0.025 \mathrm{M}, 0.05 \mathrm{M}, 0.075 \mathrm{M}$ and $0.10 \mathrm{M}$ in the equilibration temperatures between $30.0^{\circ} \mathrm{C}$ to $45.0^{\circ} \mathrm{C}$ as explained ${ }^{13}$.After 3 hours, the amount bromide and iodide ions ${ }^{15}$ exchange with the resin can be determined potentiometrically ${ }^{14-15}$ by using standard 0.1 $\mathrm{M} \mathrm{AgNO}_{3}$.

$$
\mathrm{A}-\mathrm{Cl}+\mathrm{Br}_{(\mathrm{aq})} \rightarrow \mathrm{A}-\mathrm{Br}+\mathrm{Cl}_{(\mathrm{aq})}^{-}
$$

Table1: Physico-chemical properties ofAuchliteARA-9366

\begin{tabular}{|c|c|c|c|c|c|}
\hline $\begin{array}{l}\text { Name of } \\
\text { Resin }\end{array}$ & $\begin{array}{l}\text { Type of } \\
\text { Matrix }\end{array}$ & $\begin{array}{l}\text { Functional } \\
\text { Group }\end{array}$ & $\begin{array}{l}\text { Average particle } \\
\text { Size }(\mathrm{mm})\end{array}$ & $\begin{array}{l}\text { Percentage of } \\
\text { Moisture }\end{array}$ & $\begin{array}{c}\text { Rage of operating } \\
\text { temperature }\left({ }^{\circ} \mathrm{C}\right)\end{array}$ \\
\hline $\begin{array}{l}\text { Auchlite } \\
\text { ARA9366 }\end{array}$ & $\begin{array}{l}\text { Polystyrene- } \\
\text { divinyl benzene }\end{array}$ & $\sim \mathrm{R} 4 \mathrm{~N}+, \mathrm{OH}-\sim$ & $0.3-0.9$ & $40-50$ & $50-60.0$ \\
\hline
\end{tabular}




$$
\mathrm{A}-\mathrm{Cl}+\mathrm{I}_{(\mathrm{aq})}^{-} \rightarrow \mathrm{A}-\mathrm{I}+\mathrm{Cl}_{(\mathrm{aq})}^{-}
$$

Where $A=$ AuchliteARA-9366

From the results the equilibrium constants $K$ for the reaction (I) and (II) were calculated in the equilibration temperature ranging from $30.0^{\circ} \mathrm{C}$ to $45.0^{\circ} \mathrm{C}$.

\section{RESULTS AND DISCUSSIONS}

The equilibrium constants $(K)^{16}$ for reactions I and II were calculated by the equation

$$
K=[\mathrm{A}-\mathrm{X}]\left[\mathrm{Cl}^{-}\right] \overline{[B-\mathrm{A}-\mathrm{X}]\left[\mathrm{X}^{-}\right]}
$$

Here, $A=$ AuchliteARA-9366 surface; $B=$ anion exchange capacity of the resin; $\mathrm{X}=\mathrm{Br}$ and 1 - ions. Thus by knowing different concentrations of $\mathrm{X}$-ions in solution at a given temperature, equilibrium constant $(\mathrm{K})$ values were calculated and mean

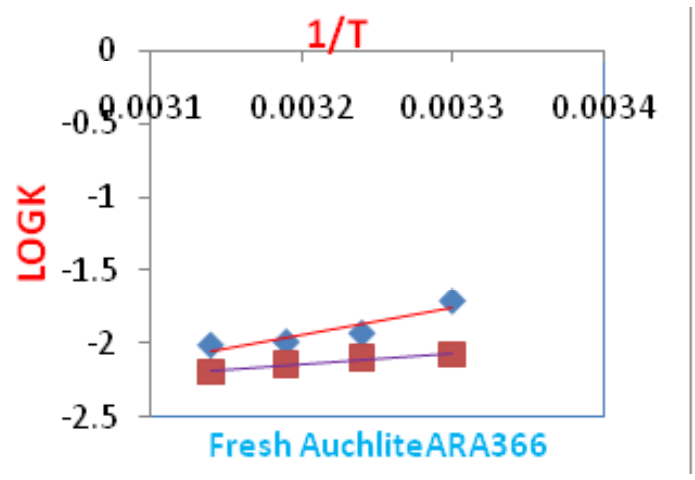

$K$-values for this set of experiment was determined. Similar $K$ values were calculated for the $\mathrm{Cl} / \mathrm{Br}$ and $\mathrm{Cl}^{-} / \mathrm{I}^{-}$ion exchange reactions carried out at different temperatures. A graph was plotted in between $\log K$ and $1 / \mathrm{T}\left({ }^{\circ} \mathrm{K}\right)$ (figure1-3), from the slope of a graph, the standard enthalpy change $\Delta \mathrm{H}^{\circ}, \Delta \mathrm{G}^{\circ}$

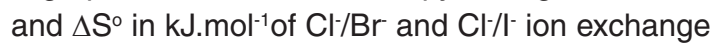
reactions were determined for $K$-values at different temperatures. Similarly $\ddot{\mathrm{A}} \mathrm{H}^{\circ}, \mathrm{ÄG}^{\circ}$ and $\mathrm{A}^{\circ}$ and equilibrium constant $(\mathrm{K})$, for the above $\mathrm{Cl} / \mathrm{Br}$ and $\mathrm{Cl}^{-/ l^{-}}$ion exchange reactions were also determined for the resin subjected to degradation in hydrogen peroxide $\left(20 \% \mathrm{H}_{2} \mathrm{O}_{2} \& 30 \% \mathrm{H}_{2} \mathrm{O}_{2}\right)$ medium. The thermodynamic parameters calculated for $\mathrm{Cl} / \mathrm{Br}$ and $\mathrm{Cl}^{\prime} / \mathrm{l}^{-}$reactions of fresh resinsAuchliteARA-9366 and resins exposed to degradation in hydrogen peroxide $\left(20 \% \mathrm{H}_{2} \mathrm{O}_{2} \& 30 \% \mathrm{H}_{2} \mathrm{O}_{2}\right)$ medium were represented in Tables 2 to 5 .

For $\mathrm{Cl}^{-} / \mathrm{l}^{-}$and $\mathrm{Cl}^{-} / \mathrm{Br}^{-}$ion reactions ${ }^{17}$, the equilibrium constant $(K)$ values for AuchliteARA-

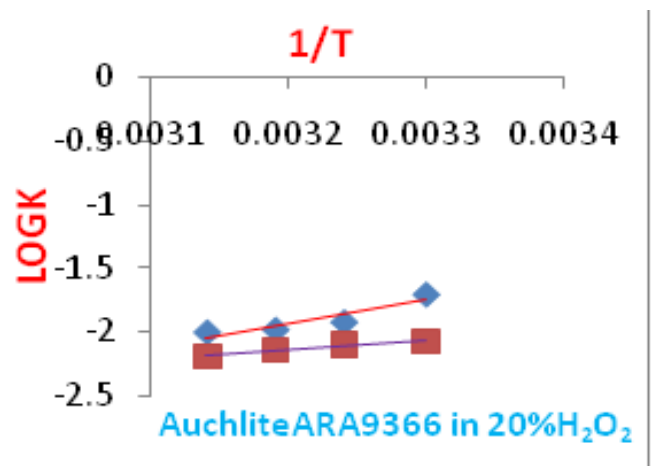

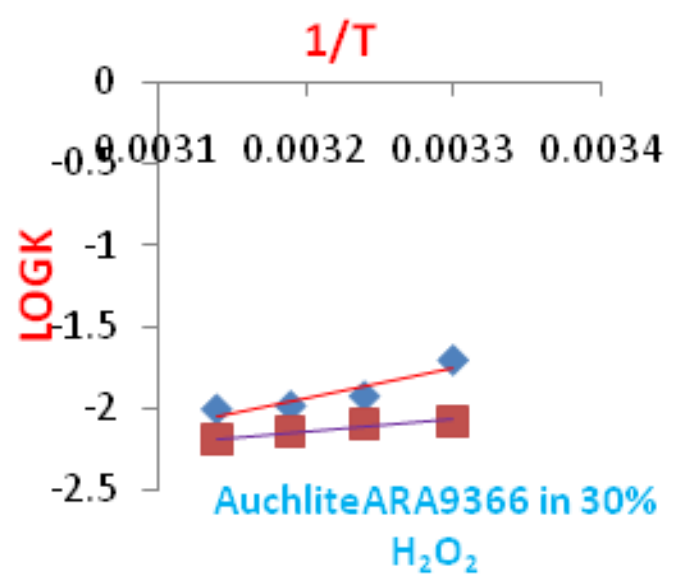

Fig. 1-3: ShowsVariation of equilibrium constant for $\mathrm{Cl}-/ \mathrm{l}-\& \mathrm{Cl} / \mathrm{Br}$-reaction.with temperature for fresh, in 20\% H2O2, and 30\% $\mathrm{H} 2 \mathrm{O} 2$ medium for AuchliteARA-9366. 


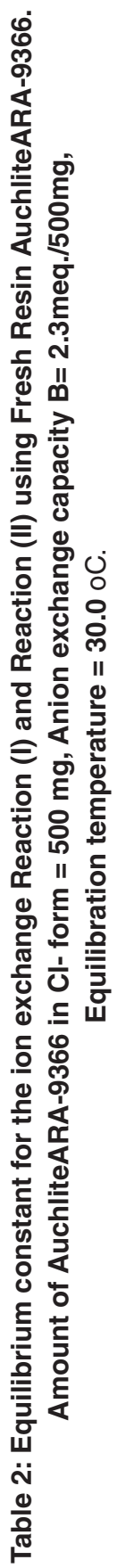

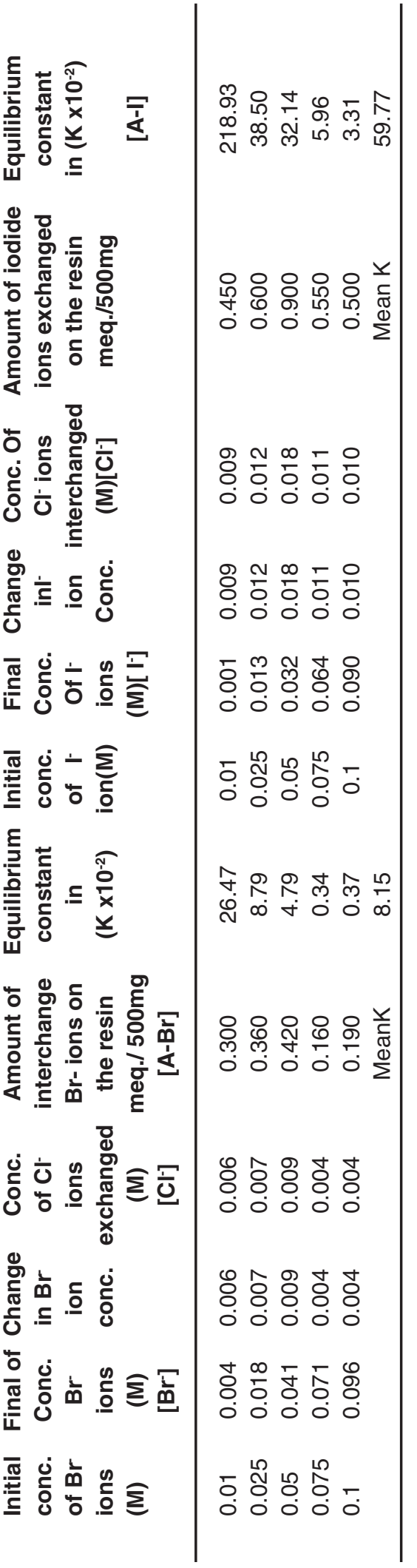




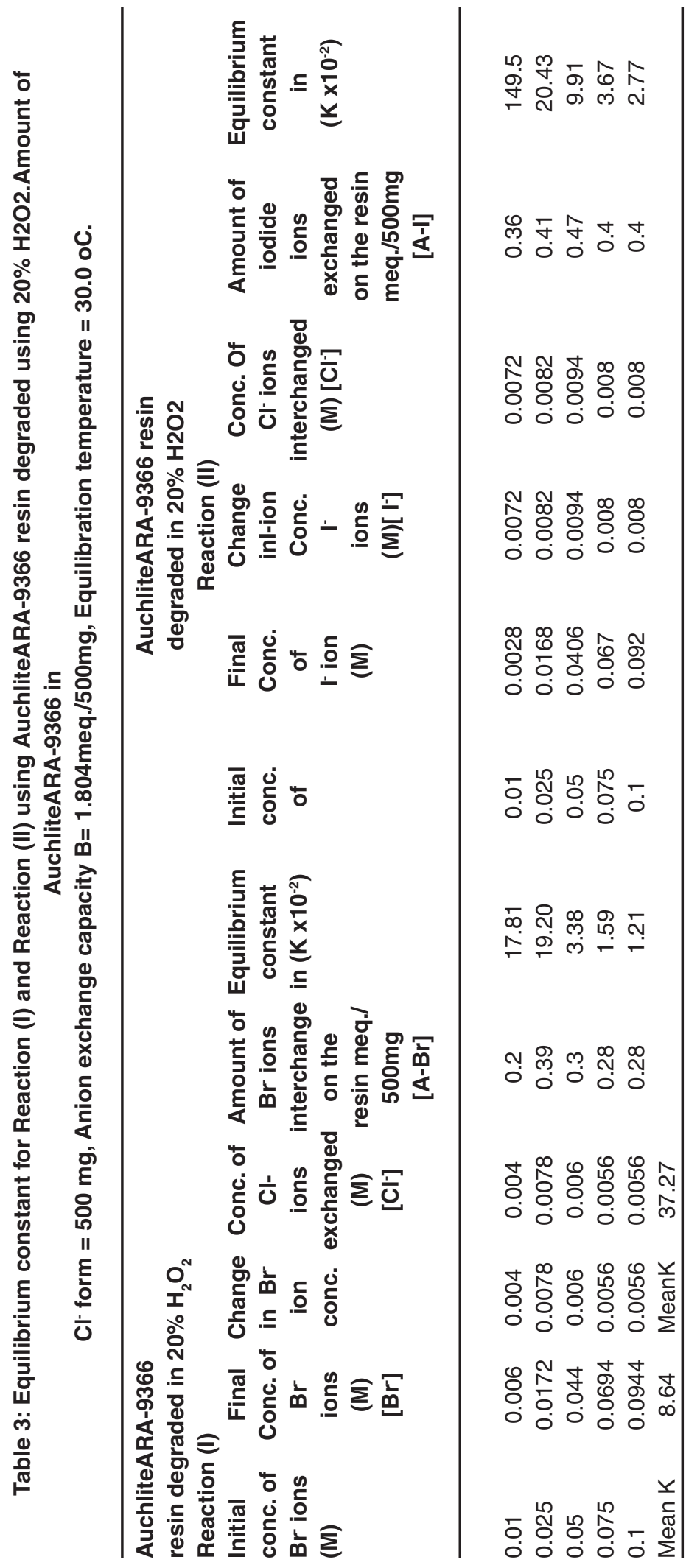




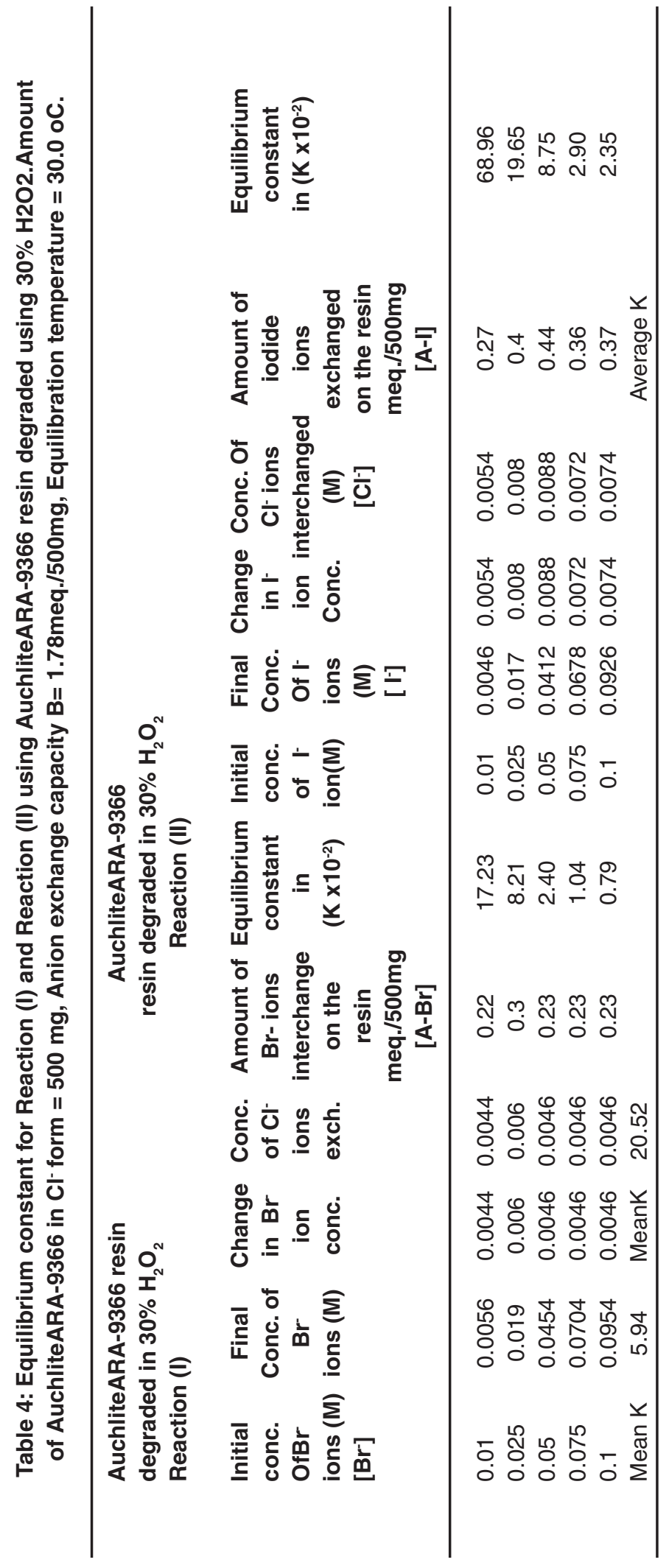


Table 5: Thermodynamics of $\mathrm{Cl}-/ \mathrm{Br}$-and $\mathrm{Cl}-/ /$-reactions using fresh AuchliteARA-9366 and degraded resin in $20 \%$ and $30 \% \mathrm{H} 2 \mathrm{O} 2$ medium.

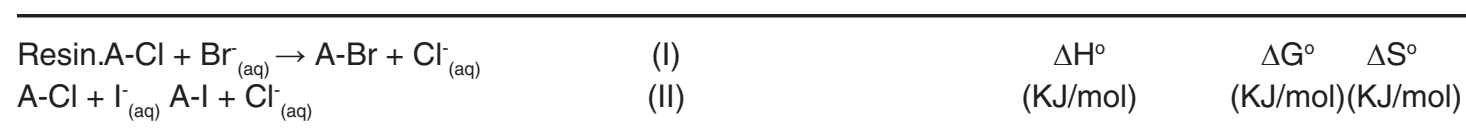

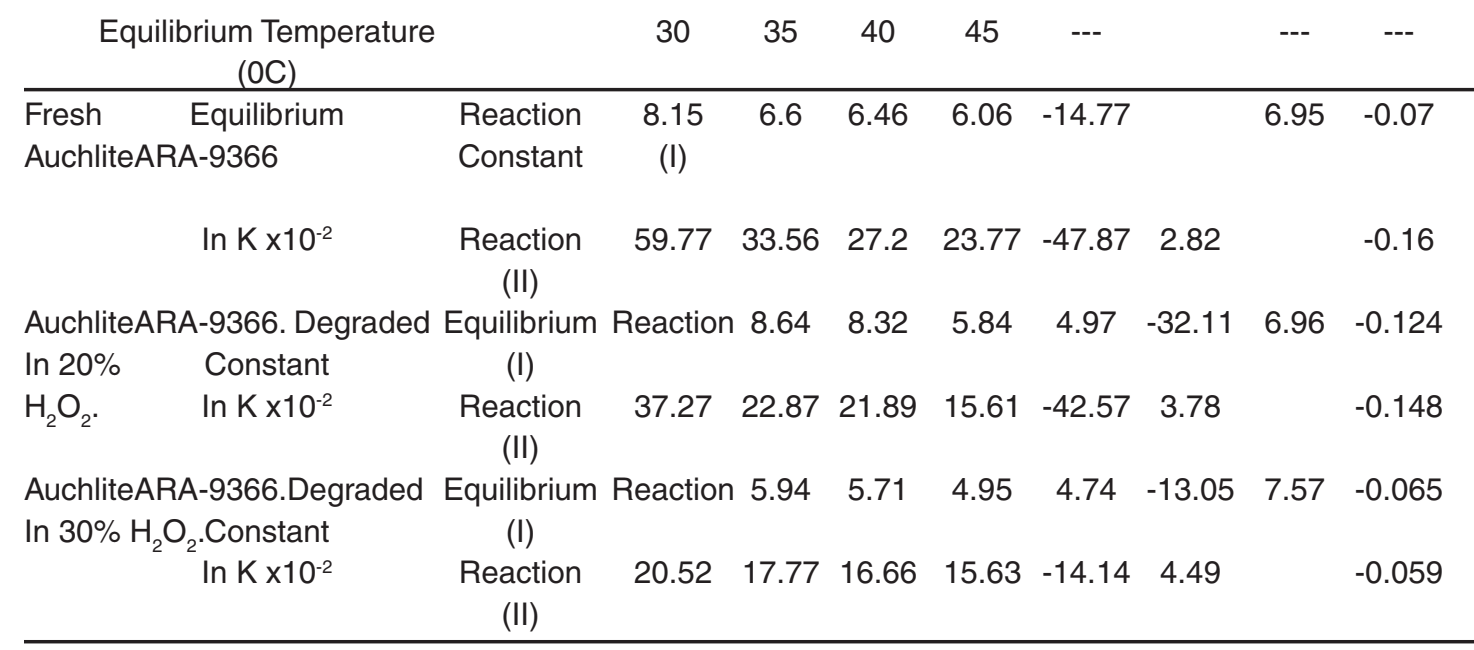

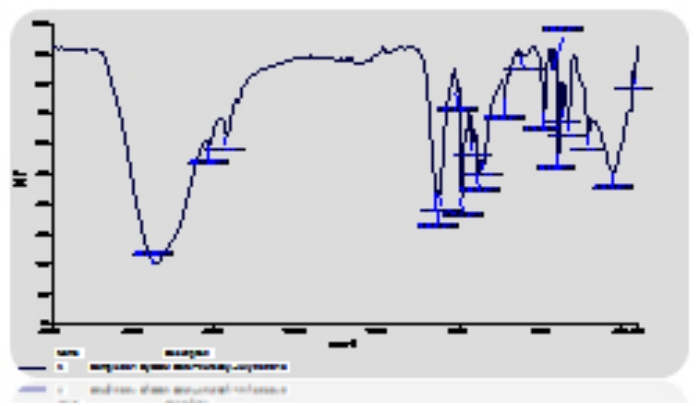

Fig. 4

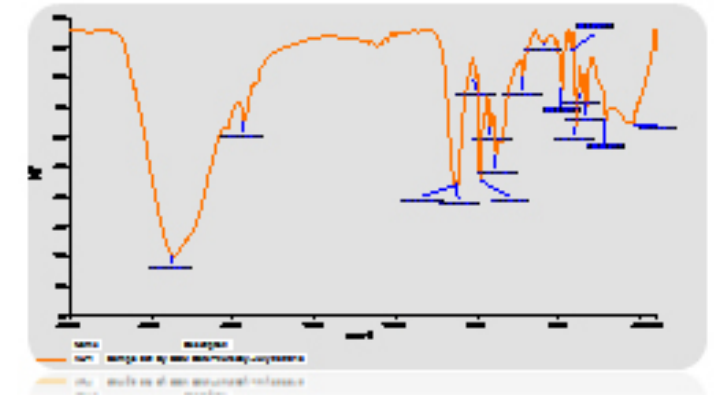

Fig. 5

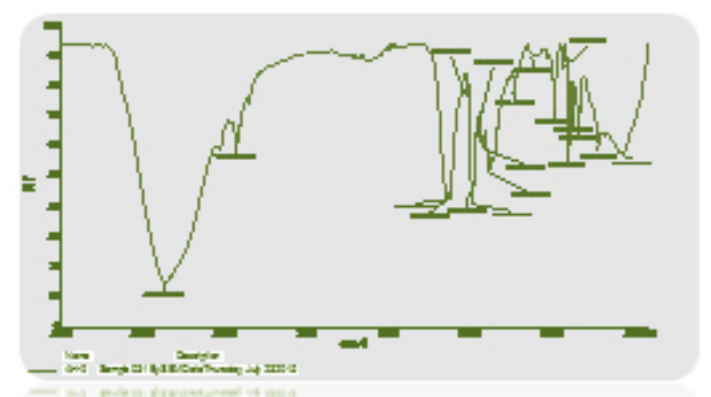

Fig. 6

Fig. 4-6.FTIR Spectrum of freshresin,chemically degraded in $20 \%$ and $30 \% \mathrm{H} 2 \mathrm{O} 2$ medium AuchliteARA-9366. 
9366 resins degraded in $20 \% \mathrm{H}_{2} \mathrm{O}_{2}$ medium were found to decreases from $37.28 \times 10^{-2}$ to $15.61 \times 10^{-2}$ and from $8.64 \times 10^{-2}$ to $4.97 \times 10^{-2}$ respectively with rise in equilibration temperature from $30.0^{\circ} \mathrm{C}$ to $45.0{ }^{\circ} \mathrm{C}$. The standard enthalpy change $\left(\Delta \mathrm{H}^{\circ}\right)$, $\left(\Delta \mathrm{G}^{\circ}\right)$ and $\left(\Delta \mathrm{S}^{\circ}\right)$ calculated for $\mathrm{Cl}^{-/} \mathrm{l}^{-}$ion exchange reactions were $-42.58,3.78$ and $-0.15 \mathrm{~kJ}^{-1} \mathrm{Kol}^{-1}$ respectively which were less than the respective values of $-32.12,6.96$ and $-0.12 \mathrm{~kJ}^{-1} \mathrm{~mol}^{-1}$ respectively as that obtained for $\mathrm{Cl} / \mathrm{Br}$ ion exchange reactions (Table 5).similarly $(K)$ values for $\mathrm{Cl}^{-/} /$and $\mathrm{Cl} / \mathrm{Br}$ ion exchange reactions for AuchliteARA-9366 resins degraded in $30 \% \mathrm{H}_{2} \mathrm{O}_{2}$ medium were found to decreases from $20.53 \times 10^{-2}$ to $15.64 \times 10^{-2}$ and from $5.94 \times 10^{-2}$ to $4.74 \times 10^{-2}$ respectively with rise in equilibration temperature from $30.0^{\circ} \mathrm{C}$ to $45.0^{\circ} \mathrm{C}$. The standard enthalpy change $\left(\Delta \mathrm{H}^{\circ}\right),\left(\Delta \mathrm{G}^{\circ}\right)$ calculated

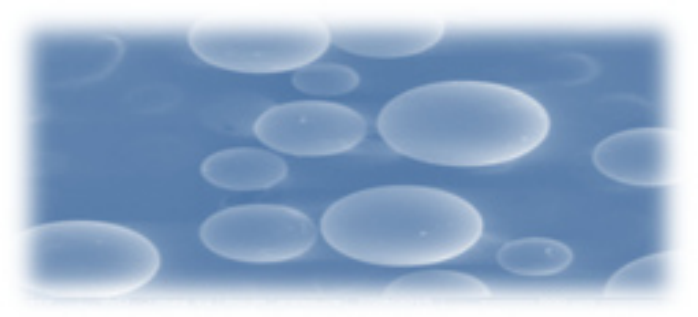

Fig. 7:SEM image offresh resinAuchliteARA9366 in 20\% $\mathrm{H} 2 \mathrm{O} 2$

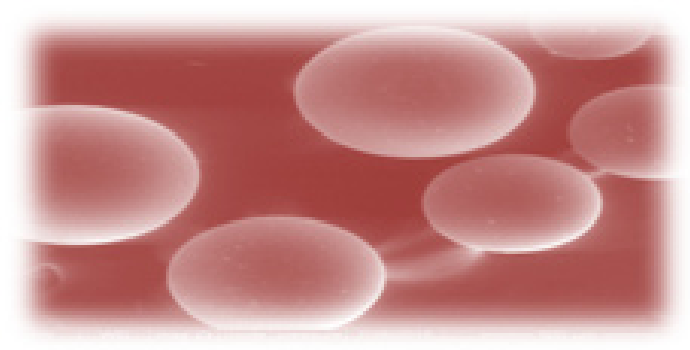

Fig. 8: SEM of chemically degraded

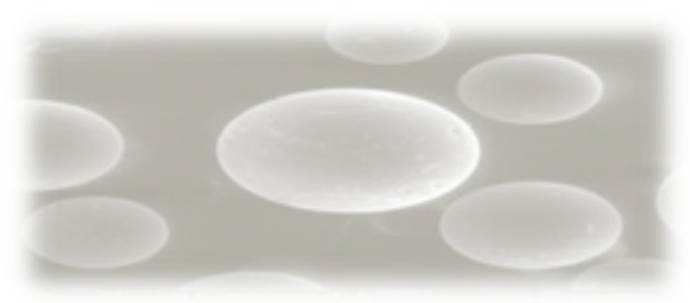

Fig. 9: SEM image of AuchliteARA-9366 resin chemically degraded using $30 \% \mathrm{H} 2 \mathrm{O} 2$ for $\mathrm{Cl}^{-} / \mathrm{l}^{-}$ion exchange reactions were -14.14 and $4.50 \mathrm{~kJ} \mathrm{~mol}^{-1}$ respectively which were lower than the respective values of -13.05 and 7.58 in $\mathrm{kJ}^{-\mathrm{mol}^{-}}$ ${ }^{1}$ respectively as that obtained for $\mathrm{Cl} / \mathrm{Br}$ reactions. However, slightly large value of $\left(\Delta S^{\circ}\right)-0.06 \mathrm{kJmol}^{-}$ ${ }^{1}$ is obtained for $\mathrm{Cl}^{-/}$- ion exchange as compared to -0.07 kJ.mol-1 obtained for $\mathrm{Cl} / \mathrm{Br}$ ion exchange reactions (Table 5 ). The large $K$ values and standard enthalpy change $\left(\Delta \mathrm{H}^{\circ}\right),\left(\Delta \mathrm{G}^{\circ}\right)$ and $\left(\Delta \mathrm{S}^{\circ}\right)$ values [as given in Tables 5] obtained for $\mathrm{Cl}^{-} / \mathrm{l}$-ion exchange reactions as compared to the $\mathrm{Cl} / \mathrm{Br}$ ion exchange reaction for fresh and peroxide degraded AuchliteARA-9366 in 20\% $\mathrm{H}_{2} \mathrm{O}_{2}$ and $30 \% \mathrm{H}_{2} \mathrm{O}_{2}$ medium shows that iodide ions in the solution were more selective towards the resins AuchliteARA-9366 as compared to that of bromide ions. Similarly for $\mathrm{Cl}^{-} / \mathrm{I}^{-}$and $\mathrm{Cl} / \mathrm{Br}$ - reactions of chemically degraded resin AuchliteARA-9366, the K-values obtained were nearly half of equilibrium constants $(K)$ values obtained for $\mathrm{Cl}^{-/ /}$and $\mathrm{Cl} / \mathrm{Br}$ - reactions of fresh resins AuchliteARA-9366 with rise in the concentration of hydrogen peroxide from $20 \%$ to $30 \%$. these equilibrium constants $(\mathrm{K})$ values for AuchliteARA-9366 resins decreases with increase in the concentration of hydrogen peroxide indicating that the resin oxidized effectively in peroxide medium which were clearly seen in FTIR spectrum and SEM Micrograph ${ }^{18}$ of the resins under similar conditions.

\section{FTIR spectrum of fresh and chemically degraded AuchliteARA-9366 resin using hydrogen peroxide}

FTIR spectra of fresh as well as Hydrogen peroxide degraded samples of AuchliteARA-9366 resins were recorded in $\mathrm{KBr}$ pellets (0.002 $\mathrm{g}$ resin/ $0.200 \mathrm{~g} \mathrm{KBr}$ ) were using a PerkinElmer $1750 \mathrm{FTIR}$ spectrophotometer. In the FTIR spectrum of fresh resin[19] AuchliteARA-9366, the sharp strong broad band at $3366 \mathrm{~cm}^{-1}$ corresponding to the signal vibration of $\mathrm{O}-\mathrm{H}$ bond of the water or the quaternary ammonium group $\left(\mathrm{R}_{4}-\mathrm{N}^{+}\right)$. This may be due to the moisture content of the fresh resins. The sharp band between $1380-1349 \mathrm{~cm}^{-1}$ is for $-\mathrm{C}-\mathrm{N}$ stretching while a variable absorption bands between 1633$1614 \mathrm{~cm}^{-1}$ is due to the stretching vibrations of $-\mathrm{C}=\mathrm{C}$ - of alkenes group. The weak band at $3031 \mathrm{~cm}^{-1}$ is the characteristic stretching band for aromatic ring. A moderate band at $2925 \mathrm{~cm}^{-1}$ is due to the $\mathrm{C}-\mathrm{H}$ stretching band for $-\mathrm{CH}_{2}$ group. A moderate and sharp band at $1416 \mathrm{~cm}^{-1}$ and $1470 \mathrm{~cm}^{-1}$ is due 
to the $-\mathrm{C}-\mathrm{H}$ bending bands for $-\mathrm{CH}_{2}$ group. The variable band at $1511 \mathrm{~cm}^{-1}$ is the $-\mathrm{C}=\mathrm{C}$ - stretching for aromatic ring, the sharp band at $828 \mathrm{~cm}^{-1}$ and moderate band at $705 \mathrm{~cm}^{-1}$ is the characteristic bands of p-substituted and o-substituted aromatic rings. On Comparing the IR spectra of fresh resin (figure 4) with the IR spectra's of degraded resin in $20 \%$ and $30 \%$ peroxide medium (figure 5and 6 ) indicate the disappearance of characteristic -C-N stretching ${ }^{19}$ in quaternary ammonium group band at $1349 \mathrm{~cm}^{-1}$ and the characteristic Aromatic $-\mathrm{C}-\mathrm{H}$ stretching band at $3031 \mathrm{~cm}^{-1}$, it can be conclude that the resin is slightly oxidized in the peroxide medium and there is no significant change in structure of the resin. However, some of the resin sites are blocked or cracked for the ion exchange reaction with rise in the concentration peroxide degradation medium from $20 \%$ to $30 \%$ which can also be seen in the SEM images(figures 8-9) of peroxide degraded resins.

Scanning electron micrographs of both fresh and degraded resin surfaces were obtained with the help of SEM technique using Scanning Electron Microscope of model no. JSM-6380LA (Jeol Ltd., Japan). The resin samples were properly placed on the aluminum sub coated double-sided graphite tape and simultaneously samples were made exposed electronically in a vacuum on thin carbon layer for 60 seconds at $30 \mathrm{~W}$. The images were captured at an excitation voltage of 15 $\mathrm{kV}^{20}$ under a 90 Pascal pressure and a magnification of $x 150, x 500, x 1000, x 2500$ and $\times 5000$. The SEM (Figure 7) of fresh ion exchange resins AuchliteARA9366 shows its plane spherical structure with smooth surface. The scanning electron micrograph of chemically degraded AuchliteARA-9366 resin in $20 \% \mathrm{H}_{2} \mathrm{O}_{2}$ medium shows large hair line cracks and thread like rough appearance on the plane surface of the resin indicates the resin may be mildly oxidized in the peroxide medium (Figure 8) while SEM image of chemically degraded AuchliteARA-9366 resin in $30 \% \mathrm{H}_{2} \mathrm{O}_{2}$ medium shows heavy cracks and dots on the plane spherical surface of the resin indicates that the resin may be oxidized in the peroxide medium (Figure 9) and the surface of the resin is appearing still rough in the peroxide medium as compare to that of fresh resin (Figure 7).

\section{CONCLUSION}

The present research work will be helpful for understanding the degradation effect of various oxidizing and reducing agents on the performance and selectivity behavior of different industrial and nuclear grade resin materials for treatment of waste water effluents. The results and data obtained from such research work will be helpful in selecting the specific ion exchange resins for efficient industrial applications and will be useful in optimization of process parameters to achieve the maximal efficiency of the ion exchange material.

\section{REFERENCES}

1. Wiley, J. ; and sons. Inc. J.Appl polym Sci. 1997, 64; 1161-1167.

2. Baumann, E. ; J. Chem. and Eng. Data, 1960, 5, 376 .

3. Singare P.U; Patange,A.N.; International Letters of Chemistry, Physics and Astronomy, 2014,11, 67.

4. Singare P.U; Patange,A.N.;, International Letters of Chemistry, Physics and Astronomy, 2014, 11, 44 .

5. Singare P.U; Patange,A.N.; International Letters of Chemistry, Physics and Astronomy, 2014, 6, 8.

6. Singare P.U; Patange,A.N.; International Letters of Chemistry,Physics and Astronomy,

\section{4,6, 1.}

7. International atomic energy agency, Waste Treatment and Immobilization, Techniques Involving Inorganic Sorbents IAEA-TECDOC947, Vienna 1997.

8. Bhargava, A.; Janardanan, C.; Indian J.Chem.,1997,36A, 624 .

9. Lokhande,R.S.; Singare,P.U.; Patil ,A.; Russ. J. Phys. Chem. A,2007,81,2059.

10. Singare,P.U; Lokhande ,R.S.; Prabhavalkar, T.Bull. Chem. Soc. Ethiop.,2008,22:415 .

11. Lokhande, R.S.;Singare, P.U.; Patil,A.B.; Radiochim. Acta,2007 95: 111.

12. Lokhande,R.S.; Singare, P.U; Radiochim. Acta, 2007,95,173. 
13. Lokhande,R.S.;Singare,P.U.; J .Porous Mater, 2008, 15, 253.

14. Hatsis,P.; Lucy, C.A.; J. Chromatogr., 2001,920A, 3 .

15. McNeill,I.C.;Mohammed,M.H.; Polym. Degrad. Stab. , 1995,48,175.

16. Decker, C.; Zahouily,K.; Polym. Degrad. Stab. , 1999, 64,293.
17. Santhiya, D.; Subramanian,S.; Natarajan ,K.A.; Malghan,S.G.; J. Colloid. Int. Sci., 1999,216,143.

18. Kaczmarek,H.; Felczak,A.; Szalla,A.; Polym. Degrad. Stab. ,2008, 93,1259 .

19. Jiang,D.D.;Yao,Q.;McKinney,M.A.;Wilkie,C.A .; Polym. Degrad. Stab.,1999,63, 423 .

20. Singare, P.U.; lonics, 2014,20, 867 . 